\title{
TRANSPORT MODELING WITH A PURPOSE: HOW URBAN SYSTEMS DESIGN CAN BRIDGE THE GAPS BETWEEN MODELING, PLANNING, AND DESIGN
}

\author{
ROBERT B. BINDER ${ }^{1}$, ZACHARY LANCASTER ${ }^{2}$, MICHAEL TOBEY ${ }^{1}$, \\ PERAPHAN JITTRAPIROM ${ }^{1} \&$ YOSHIKI YAMAGATA $^{1}$ \\ ${ }^{1}$ National Institute for Environmental Studies Japan, Japan \\ ${ }^{2}$ School of Architecture, College of Design, Georgia Institute of Technology, USA
}

\begin{abstract}
A new age of mobility is upon us, and the way we analyze our transportation network and future development projects must move into this new age. Large-scale changes to our transportation system are coming with the introduction of disruptive technologies and services like autonomous vehicles, electric vertical take-off and landing (eVTOL) air taxis, and Mobility-as-a-Service (MaaS) platforms. Transportation modeling has long been used as a tool to measure the impact, positively or negatively, of a proposed network change or new land development. Transportation modeling has become more complex as it has shifted from the traditional four-step model, but it is still used in new development traffic impact studies, activity-based models, and most recently, agent-based models like those of MATSim. This increased complexity has made way for more comprehensive measures of effectiveness that can be useful in planning and design. However, there tends to be a gap between design occurring, tool utilization, and actual implementation of new technologies and big data effectively into these proven modeling and simulation platforms. Among five specific issues in travel forecasting, modeling is used as a reactive tool instead of a proactive tool with the purpose of influencing design and planning. Urban Systems Design has the potential to fill these gaps in methodology, which are occurring together in the modeling, planning, and design professions. An example of these new methodologies is presented using the city of Urawa Misono in metropolitan Tokyo, Japan, as a case study. As technology becomes more enhanced, so shall our methodologies, as we attempt to enact system changes in a more complex way. The feedback loop of analysis and design within Urban Systems Design methodologies could produce greater outcomes for the transportation network, for new development, and increase both the mobility and accessibility for the users of our urban networks.
\end{abstract}

Keywords: transportation modeling, urban systems design, design, smart city, big data, MATSim, travel demand modeling, traffic impact analysis, planning support system, Tokyo.

\section{INTRODUCTION}

Over time, professionals must grow with the technology available and the needs of their constituents by refreshing their own processes. It is possible that without those necessary refreshments, the processes could be losing their original purpose, and could be causing more negatives than positives for constituents without recognition. The purpose of this paper is to reflect on the transportation planning and design practices and, based on known issues with analysis, data, and overall process becoming increasingly apparent, to recommend a different approach based on known issues with analysis, data, and overall process becoming more apparent. The American Planning Association's American Institute of Certified Planners (AICP) code of ethics and professional conduct states that "our primary obligation is to serve the public interest and we, therefore, owe our allegiance to a conscientiously attained concept of the public interest that is formulated through continuous and open debate". The code goes further to state that "we owe diligent, creative, and competent performance of the work we do in pursuit of our client or employer's interest. Such performance, however, 
shall always be consistent with our faithful service to the public interest" [1]. These are the first two principles stated in the code, which every planning professional should ethically abide by. However, the pressures of the consulting industry from developers and the politics of the public sector have led some to move away from these principles over time. This driving issue is similar to the "policy resistance" in system dynamics that is described by John D. Sterman:

We are unaware of the majority of the feedback effects of our actions. Instead, we see most of our experience as a kind of weather: something that happens to us but over which we have no control. Failure to recognize the feedbacks in which we are embedded, the way in which we shape the situation in which we find ourselves, leads to policy resistance as we persistently react to the symptoms of difficulty, intervening at low leverage points and triggering delayed and distance, but powerful feedbacks. The problem intensifies, and we react by pulling those same policy levers with renewed vigor, at the least wasting our talents and energy, and all too often, triggering an unrecognized vicious cycle that carries us farther and farther from our goals [2].

As travel forecasting models are commonly used to predict the flows and conditions that result from the interaction between demand for travel by transportation system users and the travel operations that the system supplies to the users [3]-[5], there have become "standard" practices that lack critical thinking of the process that produces the final results of said analyses. Transportation modeling is meant to impact planning and design, and therefore the public interest, in a positive manner - using the travel forecasting models to be purposeful, instead of reactive, in design - but over time have become less standardized as assumptions within the models have become more flexible.

Further, there is a lack of understanding and use of the tools and data that are available in practice today. As technology and data collection practices change, the industry needs to improve the process for which we use to evaluate transportation and development projects. New mobility types, from the small-scales of ridesharing, bike-sharing, and shared scooters, to autonomous vehicles and intraurban electric Vertical Take-off and Landing (eVTOL) vehicles are planned to enter the mobility market in the next decade [6]; therefore, the modeling, travel forecasting, and design professions must improve the way data and inputs are utilized and how the overall process functions to keep pace with technological growth.

While we certainly do not seek to consider transportation planning, traffic engineering, and design consultants as unethical in this paper, we do seek to call out what has become a broken process of analyses that puts private sector site developers (client), and other shortsighted thinking, ahead of the public interest. This paper highlights the problems of data locality and algorithmic models in design work, the problems in analyses caused by outdated process and client pressures, and the problems of whether modeling is meant to be reactive or proactive tools and how these tools can better integrate with design. Within these specific topics, there are five key issues introduced (Sections 2-4) that could potentially be addressed by the introduction of Urban Systems Design highlighted by the Urawa Misono design project in Metropolitan Tokyo (Section 5).

\section{ANALYSIS AND RESULTS: THE PROBLEMS OF CLIENT PRESSURES AND STATIC, AGGREGATE, AND DETERMINISTIC MODELS}

Travel forecasting models can take on many different forms, depending on the intended use, the available and useable data for inputs and assumptions, and the tools, whether open-source 
or not. Conventional travel forecasting models date back to the late 1960s and are characterized by static, aggregate, and deterministic supply and demand modules and relationships [5]. The four-step model is the standard, and most simplified, version of a travel forecasting model with the steps of Trip Generation, Trip Distribution, Mode Choice, and Route Choice (or Trip Assignment) which provide the mechanism to determine equilibrium flows in a particular network [7]. Over time, there have been modeling advancements on both the supply-side and the demand-side, moving from static to dynamic considering the traveler choices of time, mode, and chosen route, from aggregate to disaggregate considering the individual traveler or household as an agent instead of a part of a more generalized population, and from deterministic to stochastic considering the minor to major changes that can happen to both demand and available supply as travelers make different choices [5]. However, these advancements in travel forecasting and modeling have not been represented in practice, aside from many regions moving to activity-based travel demand models [8]. It is important for researchers, consultants, and both public and private sector clients to understand the availability of data and tools and the advancements happening in the industry to implement stronger, more useful models in the future (Fig. 1).

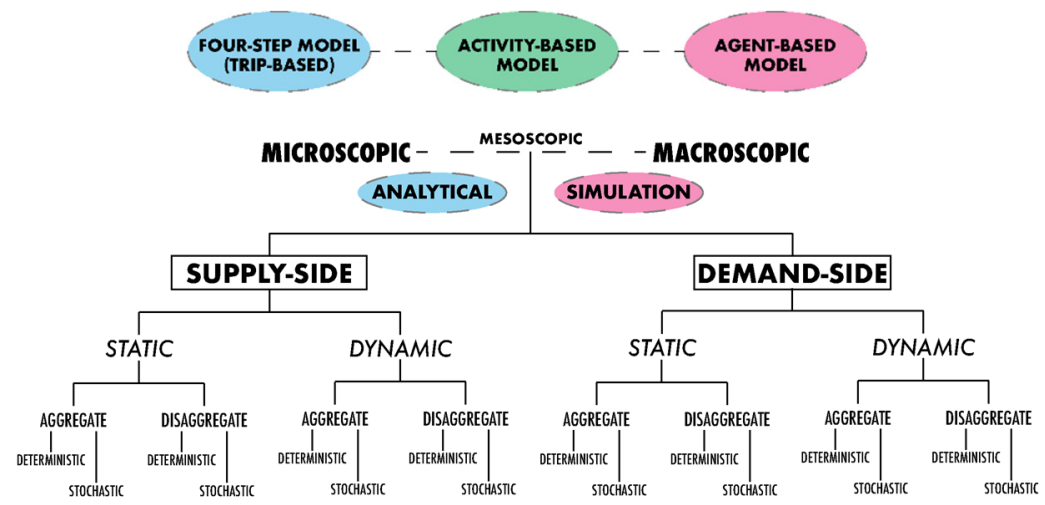

Figure 1: Transportation modeling and data formats.

\subsection{Engineering judgement or client-based assumptions}

Issue \#1 is how micro-scale private development traffic studies and macro-scale travel forecasting models are completed. Most often for microscale projects, the consultant is hired by the private developer whose obvious interest is in completing the development, so as not to let issues of traffic derail their proposal. The consultant is pressured to show a functioning roadway network which includes generated traffic from the new development, but with minimal cost to the developer. With the premise that "development should pay for the cost of providing facilities necessary to accommodate growth" in the form of impact fees [9], which are imposed fees on developers used to offset public costs caused by new traffic growth [10], these adjustments in modeling are allowing developers to avoid these types of fees and project delays. The municipality should hire the consultant, instead of the developer, to investigate how development may impact its surrounding area so that the best interest of the community is at the forefront of completing the analysis and evaluating the results.

If a study is showing negative value to new development, the assumptions are often adjusted without reasoning and the developer is able to avoid the costs required to build a 
more resilient-to-growth transportation network. An example of this is with the 85-story mixed-use development, Skycity, in Manila, Philippines, whose developers conducted a simplistic study that understated negative impacts and passed the burden of growth-oriented network changes onto the Metropolitan Manila Development Authority (MMDA) - an organization that was not involved in the approval of the development [11].

In the case of macro-scale public sector transit projects, there is a long history of ridership overestimation and cost underestimation, particularly in the United States. These forecasts are prepared for the federally mandated alternatives analysis of major transportation projects by transportation consulting firms and, like the traffic impact analysis method discussed (Section 3.2), have become standardized and are based on a series of oversimplified single independent steps which are actually occurring simultaneously but ordered in a certain way for computational reasons - lacking any accountability for social and economic relationships [12]. One particularly extreme example of an overestimation of ridership within an application for federal funding was for the Miami subway during the 1980s, which was forecast to service over 100,000 passengers per day, only serviced 9,000 passengers per day in its yet to be completed system [12], [13]. Today, over 30 years later, the built-out system only carries 76,500 passengers per day [14].

Wachs states that a competitive, politically charged environment for approving and completing major transportation projects has resulted in the continuous adjustment of assumptions to produce more attractive, often politically more attractive outcomes. This is similar to one that was written by Robert Moses' biographer, "'Once you sink the first stake', he would often say, 'they'll never make you pull it up'. If ends justified means and if the important thing in building a project was to get it started, then any means that got it started were justified. Furnishing misleading information about it was justified; so was underestimating its costs. Misleading and underestimating, in fact might be the only way to get a project started" [15]. The arguably unethical relationship between consultant and client, leading to assumptions and adjustments to analysis, and the overestimation/underestimation evidence in macro-scale transportation projects, are made possible by business-motivated consultants and politically motivated officials disguising the allocation of billions of dollars in grants by an illusion of technical objectivity shown in computerized forecasts of travel demand and cost placed at the central core of the debate surrounding each project [12].

\subsection{Static, aggregate, deterministic models and outdated inputs}

Issue \#2 is also related to how private development traffic analyses are completed, and how the models are generated. The models utilized for analyzing the impact of new developments to the transportation network are microscopic, analytical, static, aggregate, deterministic, and node-based in form. On the demand side, there is limited adjustment from the standardized trip generation materials, which are based on few studies completed decades ago. These materials are rarely questioned and do not give any focus to the user/demographic types or the impact of the existing network and travel patterns. On the supply-side, the vehicular routing is static, aggregate, and deterministic in form, so nearly every form of the model, aside from the potential for optimized traffic signaling, is inflexible once assumptions have been made. The results will be given for each node under study, with little attention given to how vehicles might interact with the change in network geometry or demand along the links of the roadways surrounding new development.

To understand the weaknesses of traffic impact analyses, as they exist in their current form, you must look no further than the ITE Trip Generation Manual, 10th Edition, which traffic engineers and planners use to develop their trip generation statistics for a proposed 
new development [16]. The trip generation process, within the traditional four-step transportation modeling process, provides an estimate of the number of trips to be generated by the new development [17]. Trip generation rates are applied to a variety of land uses within an area [18]. Traffic engineers and planner will often refer to the ITE manual as being the industry standard which supports their further engineering judgment used in the development of their study. Many of the trip generation rates for heavily developed land uses, such as Mid-Rise Multifamily Housing in a generally urban or suburban setting, are aided only by 30 previous studies or less to validate themselves using a basic statistical value like r-squared and standard deviation. While the Shopping Center land use has 426 studies to develop its trip generation values and directional distribution for the peak hours, with a 0.81 r-squared for the logarithmic eqn [16], these values should not be considered sufficient given the 108,000 shopping centers in the United States. Additionally, the average Gross Leasable Floor Area of the studies is $376,000 \mathrm{ft}^{2}$, while over $82 \%$ of the shopping centers in the United States are less than $100,000 \mathrm{ft}^{2}$ of leasable space [19]. Further, there is no standardized way of inputting a mode-share reduction for projects near transit, often resulting in an overestimated split of transit users - resulting in a positive gain for a developer.

A recent report from Purdue University recommended specific changes in traffic impact analyses for pass-by trips, the trips captured by a new development from existing traffic volumes, to the sources of data for trip generation, and to how growth rates, traffic counts, and crash data are used; however, these changes are only recommended for internal processes of the analysis, and not also to how these analyses are used by designers and the public [20]. It is important for forecasters, and their public sector clients, to recognize that many of the assumptions that are used as "standard" today were developed when different generations were the dominating users of our transportation system. Cities and suburbs are becoming increasingly more diverse, both socioeconomically and demographically, with the next generation of users utilizing the next generation of transportation technology [21], [22]. Aside from the modal choice itself, new ICT technologies on smartphones and reservation systems, integrated as Mobility-as-a-Service (MaaS) platforms, are causing driving competition in developing new mobility schemes which are still lacking behavioral studies on how users might make modal choices and trip decisions with these new technologies [23]. Recognizing these on-going changes should lead decision-makers and the profession to reconsider the way new development and transportation networks are studied.

\section{SPACE AND TIME: THE PROBLEMS OF DATA LOCALITY AND ALGORITHMIC MODELS IN DESIGN WORK}

The role of data and modeling as part of the process of design practice requires addressing the problem of locality. There is an assumption that data represents a neutral record. A different perspective tells us data is not neutral; data is an artifact of time, purpose and technology; it is not just a record of the past rather it is, as put by Christina Borgman, only "supposed evidence" of observed actions or activities within a moment and place [24]. No matter how large the data set, it is never free of its location in space or in time, its context, means and reasons for collection, nor its technological armature. Nor is any data set disjoint from the applications and algorithms that make that data operable, as many times the, presumed, post facto apparatus colors the means and methods of collection a priori. Critical reflection on the nature of data that serves to fuel the models for programs such as MATSim or any contemporary method of simulation and modeling clarifies a disjunction between data in theory and design praxis. It is a struggle in practice to make use of modeled outcomes due to the inherently problematized context as series of what-if and what-about questions that end up challenging the base data and its implicit assumptions. This disjunction can be viewed 
in terms of data and the ways it is situated, the fact that it is an incomplete view, and how these factors influence the algorithms used to make meaning of ever-increasing data sets.

\subsection{The situated nature of data}

Issue \#3 is that all data, no matter the claim to the contrary, is a local phenomenon. It is always a record of some moment, taken through some lens, for some reason. Even data collected about the Earth as a whole is defined by a physical vantage point, a technology of vision, a position in time and a mission [25], [26]. This situatedness requires that data be considered within that local context, what Yanni Loukissas refers to as a data setting [27], an accounting of the localized conditions of place, time, and material and social technologies that account of the whole sociotechnical data assemblage [28]. This situatedness bounds the ways that we may interrogate data, and therefore bounds the types of generated insights. The locality of data places real and discrete operational and interpretational limits on any data set. While the depth of the data may increase, its utility is still historically contingent and constrained by the limitations of its scope and context. While transportation modeling is generally location specific, which would seem to benefit from the locality of data, it is a problem when examining where model input assumptions such as trip generation come from (Section 2.1). This is especially relevant when comparing what amount of travel a development might generate in a car-dominated developed nation to a developing country, which are often using engineering, planning, and design processes from the United States or other developed nations. The way one community might utilize its transportation network could be very different from another community.

\subsection{Big data, simulation, and wicked problems}

Issue \#4 stems from the emerging use of Big Data in transportation modeling and how analysts utilize it while ignoring the position that no matter the complexity, no matter the sophistication of the algorithms, we are still creating machines for fitting curves [29]. A great deal of blind trust has been built up around Big Data and its promise to act as a source of "Truth" - that somehow, by virtue of size and perceived complexity, the data is a somehow wholly synoptic and more complete and therefore represents an a priori truth state, and that now technology has overcome the limitations of the past and now we do have all variables. Given this nature, it follows that no matter the number of data points, no data set is ever complete, and no curve can ever be fit to null data.

We very rarely consider these gaps, or even recognize their existence, and what the gaps may tell us about the problem we face. Instead, all too often the gaps, inconsistencies, errors, and biases are dismissed as unimportant, ignoring the impact that these gaps may have downstream as an algorithm, blinded to certain issues. This brings an old specter of planning work back, that of the wicked problem and the failing of a purely rational system that places full trust within its data sets without also recognizing the gaps and limitations. Data is by default inert without an operationalizing algorithm of some kind. Growing trust has been placed in the power of algorithms in themselves. This faith states that, with growing statistical complexity and capacity to deal with increasing variable spaces, the outcomes are more accurate representations of future system states. Algorithms operate upon historical data and operate to normatively construct possible alternative histories, never expected futures. This structural approach assumes that the future will be as well organized as the past; that it will follow set of given rules and that changes in material culture and social technologies will never cause singularities. 
In design and planning practices, this structured approach is problematic due to its inability to address the complexity and openness of design and planning problems. In design, problems are typically unstructured and difficult to define the variables of and have optimal, what Rittle and Webber call "wicked problems" [30]. The structural approaches of algorithms make it difficult to trust that an algorithm reveals potential solutions, for the nature of the problem it proposed to address, is by definition, unstructured. A more productive interpretation of this output is that an algorithm gives insight into the nature of the problem itself and provides a way to check if future interventions will disrupt historical patterns. This is not to be mistaken though with gleaning insights into new patterns or shifts in the underlying distributions that may arise from changes in material culture or social conditions. Rather this interpretation uses history as a means of testing possible interventions and lets that interact with the designer's intuition and local sentiments.

\section{REACTIVE OR PROACTIVE MODELING: THE PROBLEMS AND INEFFICIENCIES OF SILOED DESIGN AND TRANSPORTATION MODELING}

Travel forecasting models are used to justify or inform decision-makers if a development or transportation project fulfills the goals of the community or those goals that are more politically-driven. They are often used as an illusion of technical objectivity placed at the core of a debate surrounding a project to elevate the status of said project to the community and key stakeholders (Section 3.1) [12]. Rarely, however, do these studies change the status or major factors in a project and instead have been used as a tool to convince the public as far back as the development of the interstate system in the United States [31].

Issue \#5 is that transportation modeling has become simply a technical objective piece of the approval process for a development or transportation project, instead of a tool for better design and decision-making. The analysis happens after initial design concepts have been developed, or after the political will has been gained. But in the age of big data and with a growing number of dynamic and disaggregate agent-based simulation modeling tools becoming available [5], [24], [25], it is possible that transportation models can again become influential in both the design and success of a particular development or transportation project. With the extension of how modeling impacts design and decision-making, there would be a necessity to establish a clear set of goals and objectives for these models.

Issue \#6 stems from the lack of understanding of the capabilities of both supply-side and demand-side data integration and modeling tools, and the idea that modeling is still a reactive or visual, yet objective, way of presenting or marketing a project. With the desire to use transportation models as a way to sell a project to the public and key stakeholders, instead of using them as a way to make a project better, there is a lack of a connection between the overall goal of a project and the development of a model. Using a model in a proactive way to influence design is a factor that has been missing because of the standardization of travel forecasting. To be rational, or to use rational modeling as a backbone for analysis, one must not allow politics or capitalistic views to influence that rationality - as this would make this analysis process no longer rational.

In order to solve both of these issues (Issue \#4/Issue \#5), a method used in Urban Systems Design can be utilized. An initial transportation study should be completed in order to inform the designer of initial transportation layouts and concerns that will need to be addressed by the design. The consultant to complete this initial study could be hired from either the developer/client or the municipality, depending on the size and scale of both the municipality itself and the project to be studied. It would be preferred if the consultant is hired by the municipality to minimize business-related conflict and to place the public interest and goals at the forefront of the study. Following the initial transportation study, the designer can then 
move forward with the transportation consultant as a partner to the design team. This influence will achieve optimal transportation decisions and oversight at every step of the project, creating a feedback loop prior to review by the developer/client and the municipality. Following review, a second feedback loop occurs to achieve the highest quality of a project for the public good and the success of the project itself before final approval. This process, shown visually in Fig. 2, is one that developed naturally during the Urawa Misono design studio project that took place at Georgia Institute of Technology and in Metropolitan Tokyo, Japan, during Spring 2018, and is described in the following section.

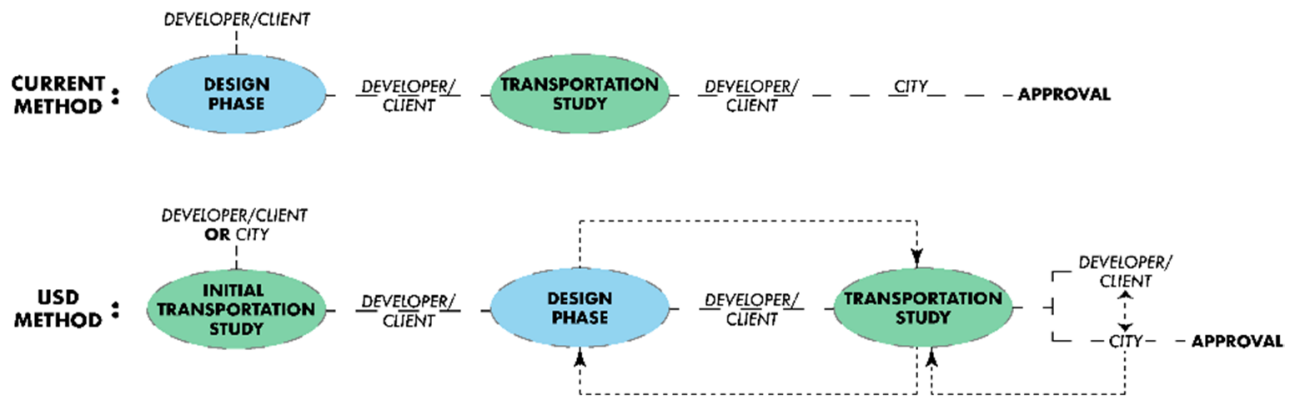

Figure 2: Transportation study process comparison (existing vs. proposed).

\section{URBAN SYSTEMS DESIGN FOR URAWA MISONO}

In 2017, students with the Georgia Institute of Technology Schools of City and Regional Planning and Architecture, at the request of the National Institute of Environmental Studies Japan and the University of Tokyo, worked to reimagine the Metropolitan Tokyo community of Urawa Misono. This project serves as an example of how starting with a systems approach and a willingness to utilize data while recognizing its limitations as a design asset, can be evolved into a flexible development system that seeks to redefine the idea of Smart Cities as locally focused flexible frameworks for urban and suburban growth. What was identified as critical was the need to create a system of generative, diagrammatic strategies that allows for the exploration of possible futures to create tactical and formal interventions, as opposed to rigid and formal plans. This project ultimately produced a vision of a possible future with a series of tactical moves played out across the corpus of the city. More importantly, the project created an initial sketch of a dynamic decision-making system that seeks to bridge decision-making scales and to manage and utilize data in a secure and trustworthy way [32].

This project serves as an early example of how Urban Systems Design can bring together designers, planners, and modelers under one set of goals for the implementation of a project. Beginning with a set of goals found through the students' attempts at public outreach, designers and modelers developed optimal typologies for both the current and future residents to achieve the larger institutional goals of net-zero and sustainable resource usage. The design was built from the initial transportation and existing conditions inventory, and then analyzed through both static and dynamic modeling platforms (such as Vissim, Visum, Rhino, and EnergyPlus) for transportation and energy usage. The results of design and analysis together led to the development of three main concepts - the Sensor-Enabled City, the Planning Support System, and Value-Driven Urban Systems Design [32]. 


\subsection{The sensor-enabled city}

The system sketched as a part of the Urawa Misono project began by looking at types of sensors, the scales at which they were deployed, and the means of data collection available to each sensor. This allowed the team to look at levels of aggregation and transparency. This network of sensors tied everything together. The maximization of autonomy at the level of devices and individuals was desired. Within this system, homes and public buildings became the cyber-physical location address for a localized data setting. Acting in a manner similar to that proposed by Dr. Berners-Lee's Data Solid project, the network of solids was overseen by a local data steward, supposed as the local urban design center, UDCMi, who could transparently oversee the use of and access to this local data by acting as a Local Data Trust, a secure singular access point (similar to a US Census Research Data Centre). This creates local accountability through a means of auditing and overseeing data and is intended to ease concerns about privacy in a world with increasing amounts of data collected and is operationalized by other entities by connecting the population to the ways in which their data is used.

\subsection{Planning support system}

This data setting was used to conceive of a system that would oversee the growth of Urawa Misono. This system, based in an algorithmic game-theory strategy, proposes a Planning Support System (PSS). The PSS represents a dynamic multi-scale management system that seeks a Nash equilibrium between objectives operating in different spatial orders. The goal is a stable, steady state, recognizing that the autonomy of actors within that system will upset that equilibrium. Each of the "pieces" represents a nominal $1 \mathrm{~km}^{2}$ city block, and a series of combinations of possible layouts, and acts as a container for specific performance outcomes. This gives designers control over the form, but also provides quantitative targets. This process keeps the design locally responsive, but globally bounded. The abstract pieces contain all of the game variables that the algorithmic engine considers which antagonistically attempts to meet its given objectives. Each algorithm considers its objective and which of the variation of the pieces best fits that objective within the context of surrounding pieces.

\subsection{Value-driven urban system design}

The Urawa Misono project sought to see the development of an urban area as a continuous state of emergence. It took the position that urban form emerges from the consequences of movements of populations, changes in material culture, and social conditions. At the same time, the system recognizes its own limits and addresses those limits by expressing value statements in the form of the objective functions written formally into the PSS. These expressions bound the decision vectors of the system itself; interventions beyond these vectors are outside the purview of the system and must be addressed ad hoc through more considered design. Other elements of the system are capable of enabling these ad hoc processes. The Local Data Trust collects and gives access to data in new ways, creating a localized ecosystem of knowledge about the community across many more vectors than the system itself is operating on while proving control over that data.

The designed urban system went beyond the formal limits of buildings and infrastructure. It took steps outside the traditions of old social technologies, one in where bottom-up and top-down are vertically integrated, where the PSS and local decisions are enabled simultaneously within the same regulatory framework. This type of value-driven system 
lowers the threshold for its utilization within design and planning, and those involved feel it would enable more dynamic and responsive policy and regulation development. The way the system communicates also enables design within system boundaries. By generating generic prototypes, the system can set dynamic formal constraints with measurable required outcomes. This can easily be tied into development financial models that give local communities more control over how and what kinds of development happen without necessarily superseding larger global objectives. This makes design and planning neither top-down nor bottom-up. Rather it makes the management of a city a dynamic interactive process of emergence by leveraging data at the right scales at the right times.

The results of the Urawa Misono project, which showed the success in utilizing rational, advocacy, and communicative methods of planning, have aided in the development of the Urban Systems Design Conceptual Framework. This framework, shown in Fig. 3, is based upon its four foundational pillars - Resiliency, Economics, Sustainability, and Human Well-Being (RESH). Using these goals and performing the three phases of contextualization, evaluation, and design within an iterative loop between analyses and professionals at different scales, much like the simpler form described in Fig. 2, "modeling with a purpose" and the end goal of smart communities through integrated design is achievable [33].

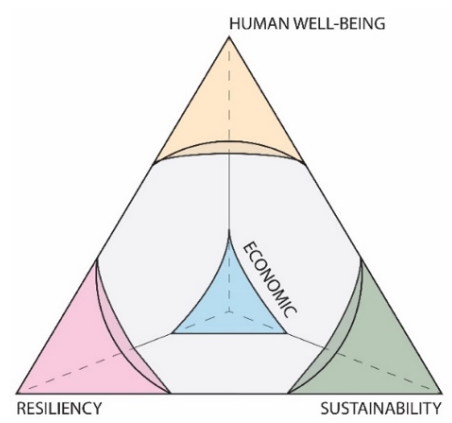

Figure 3: RESH evaluation balance [33].

\section{CONCLUSION}

The five issues discussed in this paper must be addressed in travel forecasting and transportation modeling, especially regarding how these models are used in practice. It is a challenge for any profession to change standardized practice, but if the transportation and design professions do not respond, then we risk losing control of our transportation networks as they succumb to new mobility services and technologies. There is a propensity in the transportation planning and design professions to stick with the status quo as it relates to both internal and external process. As other professions grow and morph with new technology, research, and science, the transportation planning profession stays in place and continues to use modeling and analysis in a reactive way instead of "with purpose." New data resources and modeling tools are becoming increasingly available and should become the new standard for how we perform travel forecasting and transportation modeling. With these new methods, modeling can play a more important and integrated role with design and truly work as a tool for the public good instead of an illusion of technical objectivity. The Urban Systems Design Conceptual Framework utilizes multiple planning theories - rational method, advocacy planning, and communicative planning - and merges them into one that prioritizes the four pillars of resiliency, economy, sustainability, and human well-being (RESH). This new 
framework addresses the issues with current transportation analyses and brings these analyses and design under one umbrella, as proven by the success of the Urawa Misono project in Metropolitan Tokyo.

\section{REFERENCES}

[1] APA, Principles to Which We Aspire, pp. 1-15, 2016.

[2] Sterman, J.D., All models are wrong: Reflections on becoming a systems scientist. Syst. Dyn. Rev., 18(4), pp. 501-531, 2002.

[3] Mannheim, M., Transportation Systems Analysis, Cambridge, MA: The MIT Press, 1979.

[4] Cascetta, E., Transportation Systems Analysis - Models and Applications, 2nd ed., Springer: Heidelberg, 2009.

[5] Ben-Akiva, M., Bottom, J., Gao, S., Koutsopoulos, H.N. \& Wen, Y., Towards disaggregate dynamic travel forecasting models. Tsinghua Sci. Technol., 12(2), pp. 115-130, 2007.

[6] Binder, R.B., Garrow, L.A., German, B.J., Mokhtarian, P.L., Daskilewicz, M.J. \& Douthat, T.H., If you fly it, will commuters come? Predicting demand for evtol urban air trips. Presented at 2018 Aviation Technology, Integration, and Operations Conference, Atlanta, Georgia, 2018.

[7] McNally, M.G., The four step model. Handbook of Transport Modeling, eds D.A Hensher \& K.J Button, 2nd ed., Pergamon: Irvine, CA, 2007.

[8] Bhat, C.R \& Koppelman, F.S., Activity-Based Modeling of Travel Demand, vol. 3, 2014.

[9] Ross, D. \& Thorpe, S.I., Impact fees: Practical guide for calculation and implementation, Revenue Cost, 1991.

[10] Carrion, C. \& Libby, L., Development Impact Fees; Ohio State University Fact Sheet, 2004. http://ohioline.osu.edu/cd-fact/1558.html.

[11] Teodoro, R.V.R., Traffic impact assessment for sustainable traffic management and transportation planning in urban areas. Proceedings of the Eastern Asia Society for Transportation Studies, vol. 5, pp. 2342-2351, 2005.

[12] Wachs, M., Forecasts in urban transportation planning: Uses, methods, and dilemmas. Climate Change, 11(1-2), pp. 61-80, 1987.

[13] Davidson, E.K., Few ride miami's rapid transit line even though it is clean and on time, Wall Street Journal, p. 18, 6 September, 1984.

[14] Chardy, A., Miami's metrorail at 30: Promises kept, promises broken, Miami Herald, 2014.

[15] Caro, R.A., The Power Broker: Robert Moses and the Fall of New York, Alfred A. Knopf: New York City, 1974.

[16] Institute of Transportation Engineers, ITE Trip Generation Manual, 10th ed., 2017.

[17] Villareal, F.F., Exploratory Study on the adoption of traffic impact fee in the Philippines. J. East Asia Soc., 9, pp. 1-20, 2011.

[18] Nelson, D., Traffic access and impact studies. Manual of Transportation Engineering Studies, Institute of Transport Engineers: Washington, DC, 1994.

[19] US Census Bureau, Table 1060: New motor vehicle sales and car production, 1990 to 2010; Table 1061: Shopping centers - Number and gross leasable area, 1990 to 2010; Table 1062: Food and alcoholic beverage sales by sales outlet, 1990 to 2009. Figures and statistics report, 2012.

[20] Bollinger, G. \& Fricker, J., Updated Methods for Traffic Impact Analysis, Including Evaluation of Innovative Intersection Designs, vol. 3, reviewer's guide, 2017. 
[21] Klein, N. \& Smart, M., Millennials and car ownership: fewer cars, less money. Transp. Res. Board 95th Annu., 53, pp. 20-29, 2016.

[22] Hong, J. \& McArthur, D.P., How does internet usage influence young travelers' choices? J. Plan. Educ. Res., 39(2), pp. 155-165, 2019.

[23] Schade, W., Krail, M. \& Kühn, A., New mobility concepts: Myth or emerging reality?. Transport Research Arena Conference, p. 9, 2014.

[24] Borgman, C.L., Big Data, Little Data, No Data: Scholarship in the Networked World. 2017.

[25] Haraway, D., Situated knowledges: The science question in feminism and the privilege of partial perspective. Fem. Stud., 14(3), p. 575, 2006.

[26] Kitchin, R. \& McArdle, G. What makes big data, big data? Exploring the ontological characteristics of 26 datasets. Big Data Soc., 3(1), 2016.

[27] Loukissas, Y.A., All Data Are Local - Thinking Critically in a Data-Driven Society, MIT Press, 2019.

[28] Kitchin, R. \& Lauriault, T.P., Towards critical data studies: Charting and unpacking data assemblages and their work, Think. Big Data Geogr. New Regimes, New Res., pp. 3-20, 2018.

[29] Peter, V.C., Edward, R.D. \& Roger, R.H., Big data need big theory too. Philos. Trans. R. Soc. A Math. Phys. Eng. Sci., 374(2080), 2016.

[30] Rittel, H.W.J. \& Webber, M.M., Dilemmas in a general theory of planning. Policy Sci., 4, pp. 155-169, 1973.

[31] Jackson, M.I., Model City Blues: Urban Space and Organized Resistance in New Haven, Temple University Press: Philadelphia, PA, 2008.

[32] Yamagata, Y., Yang, P. \& Murayama, A., Smart city : Urawa Misono. Urban Systems Design research report, 2017.

[33] Tobey, M., Binder, R., Chang, S., Yoshida, T., Yamagata, Y. \& Yang, P., Urban systems design conceptual framework: Modeling, design, and emergent iterative smart communities. Presented at CUPUM 2019: Computational Urban Planning and Management for Smart Cities, Wuhan, China, 2019. 